\title{
С. С. Хоружий
}

\section{Претходно саопштење \\ UDK 316.7:008(470)}

\section{ВЕК ПОСЛЕ “ВЕХ“ ИЛИ ДВЕ-ТРИ РОССИИ СПУСТЯ}

Все говорят: „Вехи“, „Вехи“! А я как ни ворошу знаменитый сборник, сколько ни вкушаю прославленных текстов - бессилен в них усмотреть эпохальное величие. Нет-нет, я не думаю хулить, просто судите сами. „Сборник статей о русской интеллигенции“. А кто-нибудь сосчитал все множество сборников статей, плодившихся, как Дон Аминадо сказал, в те баснословные года? Среди них масса была и сборников с именитыми авторами, со статьями на глубокие темы: „Свободная совесть“ (два сборника), „Вопросы религии“ (тоже два), „Сборники книгоиздательства 'Путь'“ (еще два), „О смертной казни““.. и т.д. и т.д. Жанр статей „Вех“ - публицистика, лишь изредка заходящая в философию. Какого-либо консензуса, или концепции, или единой платформы авторами не создано, в их взглядах порядочная разноголосица. Правда, с такою темой, чтобы весь сборник сплошь об интеллигенции, о всех ее сторонах и свойствах, язвах и доблестях, - такой сборник первый, это выделяет „Вехи“. Но делает ли это их более актуальными в наши дни? Ведь сам предмет этот, эта сакраментальная intelligentsia russe, сегодня уже почил, исчез и не существует. (Ниже мы обсудим еще этот факт жизни.)

И все же, при всем том, „Вехи“, без сомнения, обладают сильным воздействием, оставляют впечатление уникального явления. Не сразу ясно, чем создаются эти впечатление и воздействие; лишь постепенно осознаешь, что исток их - в том духе и настроении, которыми проникнута книга и которые уже в предисловии выразил Михаил Гершензон, сказавший, что все статьи писаны „, болью и в жгучей тревоге“. Эти тревога и боль доходят, и мы видим, что книга в целом - редчайший акт предельно честной самооценки русского сознания, критический жест уникальной подлинности и глубины. И эта чистота жеста, радикального и безжалостного к себе, идущего до конца, - не стареет. Здесь то, в чем „Вехи“ непреходящи, в чем они - пример и задание для нас. Насколько мог, я старался быть верным этому заданию.

Для критического жеста „Вех“ историческим фоном служила Русская революция, которую еще не называли Первой: ее подготовка интеллигенцией, ее последствия и уроки. Сегодня подобный жест должен выполняться на более широком фоне, на фоне всего века, что прошел после „Вех“. Главный предмет его - наше настоящее, его внутренняя критика, но эта критика должна относить себя к урокам, к вехам всего минувшего века. 
„Вехи“ - памятник мысли Серебряного Века - „века“, который создал целую эпоху в культуре, но длился при этом совсем не век, много если треть века, - и был оборван историческим срывом, катастрофическими процессами крушения Империи. Суть этих процессов видится мне так. С формированием интеллигенции особенно заостряется склонность русского сознания к крайним позициям, слабость центра и середины, умеренных конструктивных сил. Складывается конфликтная структура общественного сознания, когда во всех своих главных измерениях оно определяется оппозицией, противостоянием тех или иных антагонистических начал, сил, течений: власть - общество, охранители - радикалы, вера - неверие... Некое время вражда противостоящих групп или трендов не была главным фактором: в стране шли мощные процессы роста, вернувшаяся духовная традиция породила исихастское возрождение с новым явлением русского старчества, создавалась великая русская литература. Однако поляризация углублялась. Интеллигенция, как справедливо диагностируют „Вехи“, действовала как сильный разъедающий фермент, фермент разъединения и раскола общества. Противостоящие тренды шире и шире захватывали сознание, сходились вплотную, и их противостояние становилось из побочного - доминирующим фактором.

Таким - расколотым - пришло русское сознание к Серебряному Веку. Часто говорят, что его культура - Западно-Восточный синтез, она соединила в себе питающие воздействия европейской культуры и традиционных национально-православных истоков. Но в этот период русское сознание соединило уже в себе и совсем другое: антагонистические полюсы непримиримых оппозиций, на которых оно строилось, тренды творчески-созидательные и разрушительные. Меж ними был невозможен синтез. Их столкновение, сшибка в одном сознании вели к коллапсу этого сознания.

В социально-историческом плане, Русская революция с последовавшей Гражданской войной характеризуются как катастрофа, крушение, катаклизм. Но что значили они в горизонте национального сознания? Очевидно, что отвечающее им состояние этого сознания было патологическим; я характеризую его как эпилептический припадок - если точнее, аналог, коррелят такого припадка на социопсихологическом, макро-уровне. Близким образом расценивает его в своей „поведенческой теории революции“ Питирим Сорокин, судивший о событиях из самой их гущи. Здесь не место развертывать обоснование такой трактовки, скептики, если угодно, могут принять ее за простую метафору. Что в ней, в частности, для нас важно - это то, что из нее следует и определенное понимание предшествующего, „пред-припадочного“ состояния.

Серебряный Век был самым необычным, фантастическим временем. На недолгий срок Россия стала, как сказал Пастернак, „огромным родильным домом“, где что ни день рождались новые идеи, книги, культурные начинания, целые направления и движения в искусстве, - притом такие, что оставались в истории, что слагали основы новой культуры. Опыт приобрел немыслимую наполненность, интенсивность, зрение - остроту, время явило какой-то особый 
ход, небывалую сгущенность. „От смерти Владимира Соловьева до сегодняшнего дня“", - писал Блок в 1910 г. - „мы пережили то, что другим удается пережить в 100 лет“. И все это обнималось странным, лихорадочным состоянием или настроением, в котором смешались приподнятая возбужденность, тревожное ожидание, „апокалиптическое предчувствие“, как тогда выражались, предчувствие трагедии, катастрофы, которое очень скоро сбылось с лихвой. - Как охарактеризовать это особое состояние сознания, эту яркую его вспышку пред катастрофой, в которой оно за малый миг сумело охватить взглядом, постичь в синтезе целый необозримый мир? Суть его и природу указал пророк Серебряного Века - Достоевский, который на своем опыте описал момент aypbl, специфическое состояние сознания перед эпилептическим припадком. В рассказах об этом моменте - князя Мышкина в „Идиоте“, самого автора в „Дневнике писателя“ - мы узнаем все названные черты: в миг пред припадком больного посещает особое видение мира - внезапно мир является взору во всей всеохватности, но также - в осмысленности и красоте, взор проникает в благую суть и гармонию Мирового Целого, и созерцает это Целое в образах прекрасного. Следующий миг - припадок. Коллапс сознания.

Насущная необходимость после коллапса - реабилитация, бережное восстановление сознания и организма. Но русское сознание ждали большевистский тоталитаризм, сталинский террор, великие бедствия Великой Отечественной. Все эти испытания чаще обсуждают с внешних, событийных сторон, но в „веховской“ перспективе мы спрашиваем, прежде всего, что делалось с человеком и сознанием. Феномен тоталитаризма обычно рассматривают под углом практик власти, но я убежден, самые глубокие и губительные его проявления - в антропологии. „Банальность зла““ назвала Ханна Арендт свою книгу об Эйхмане; но, увы, зло тоталитаризма - отнюдь не только банальность. Банальный Эйхман - продукт, но очень и очень не банально - как его изготовили. Тоталитаризм открыл на опыте множество весьма мрачных истин о человеке, создал целый арсенал эффективных антропологических ноу-хау, почти безотказных технологий обработки и переделки человека. Нельзя здесь быть голословным, и я совсем кратко укажу хоть некоторые ведущие механизмы тоталитарной переплавки сознания и личности:

1) Редукция личности и идентичности. Формируется радикально урезанная идентичность, когда человек соотносит и идентифицирует себя исключительно с минимумом инстанций, определяемых идеологической машиной: Партия - Нация - Коллектив.

2) Архаизация: скатывание Человека вспять, в архаические антропоформации. Это обширный спектр явлений: отбрасывание заповеди „Не убий“, регенерация парадигм тотема и табу, стайного и стадного поведения; „большие процессы“, массовые убийства и лагеря как специфические антропотехники, возвращающие уклад, паттерны поведения примитивных сообществ, отчасти - и архаические культуры ужаса, ритуалы с человеческими закланиями. 
3) Самое же важное, на мой взгляд, - то, что я называю „анти-синергия“ или „насильственная синергия“. В синергии истинной, как говорит православное учение, человек, устремляясь к Богу, достигает соединения своих энергий с Божественными энергиями, благодатью, и благодать, действуя в нем, всецело преображает его. Со стороны взаимодействия энергий, это - так называемый синергетический эффект: поток внешней энергии порождает радикальную структурную перестройку. В тоталитарном варианте, аналогичный эффект вызывается насильственно. Идеологическая машина вторгается в сознание, вводя в него послание Большого Брата с азами тоталитарной догмы и угрозой мучительной смерти в случае ее неприятия. Вопреки воле человека, это послание начинает действовать в сознании, и огромный заряд скрытой в нем угрожающей энергии генерирует синергетический эффект - отклик сознания, его непроизвольную и необоримую подстройку к тому, что велит послание. Это и есть главное ноу-хау тоталитарной антропологии: оказывается, есть механизм предельно ускоренной полной перековки, перерождения-зомбирования человека - самоперестройка сознания при продавливании в него, под сверхвысоким давлением, четкой тоталитарной мантры. Не вдаваясь в теорию, этот механизм уж не раз описывали классики антитоталитаризма - к примеру, в финальной части „1984“, что заканчивается фразой: „Он уже любил Большого Брата“.

$$
* * *
$$

„Вехи“ - книга диагноза, книга, говорящая о давно уже шедшем кризисе русского общества и сознания, начал русской жизни. Взглянув на век после „Вех“, мы видим, что кризис тогда отнюдь не кончился; „критика духовных основ интеллигенции“, предпринятая авторами „Вех“ и единомышленниками их, не привела к его изживанию. Напротив, он стал неразлучным спутником этого века, иногда ненадолго удаляясь, но чаще обостряясь, а временами достигая катастрофичности. При этом, его ведущие формы углублялись. В „Вехах“ речь о кризисе - это речь об интеллигенции. Но какой группой или слоем можно ограничиться, если надо понять „революционный припадок“? Как оценить урон, нанесенный миллионною эмиграцией, оголившей все вершины культуры? Пришедший же вскоре советский тоталитаризм длился лет 60-70, большую часть века, и интенсивно занимался порчею человека, развивая технологии антропологической архаизации и трансформации. На фоне его прошла Отечественная Война, нанесшая страшный удар по самим биологическим основам национального организма. Сегодня наконец нет ни тоталитаризма, ни войны - казалось бы, должны остаться если только экономические кризисы, что неизбежны как мухи. Но нет. Перенесенное не прошло даром, и нам вновь приходится вести речь о кризисе русского сознания и общества, и приходится говорить о вовлечении в этот кризис еще нового уровня - уже, пожалуй, последнего. 
Мы говорили, что после революционного припадка Россия не получила остро необходимой ей реабилитации. Сегодняшняя же ситуация заставляет задуматься, не стал ли уже ущерб необратим: есть ли еще у нас сама возможность реабилитации -восстановления национального организма на уровне той России, которая входила - в своей классической культуре 19 в. - в разряд великих культур человечества. Столетие „Вех“, как любой юбилей, заставляет подбить итоги. Что стало, прежде всего, с главным героем и этой книги, и множества других писаний, „возов бумаги“ (Г.Федотов) - с пресловутою русской интеллигенцией? Наш вывод, уже высказанный выше, краток и прост: ныне она уже не существует. Этот вывод - из разряда очевидных суждений: взяв любую из признанных дефиниций интеллигенции как социальной группы, начиная с известнейшей, федотовской (,группа, движение или традиция, объединяемые идейностью своих задач и беспочвенностью своих идей“, причем идейностью, „этически окрашенной“(), мы с несомненностью констатируем отсутствие таковой группы в сегодняшнем русском социуме. Тем не менее он пока еще не воспринимается как простая банальность, а способен, напротив, вызвать возмущенные возражения. Причина - в своеобычной истории слов „интеллигенция“" и „интеллигент“ в широком сознании: в советский, преимущественно позднесоветский период они обрели некое мистифицированное и мифологизированное звучание, наделились квазирелигиозной ценностью, возвышенным смыслом (особенно если с эпитетом типа „настоящий интеллигент“) и стали совсем рядом с тем самым „подвижничеством“, которому их прямо - и вполне обоснованно - противопоставляет в „Вехах“ Булгаков. Да что - рядом! они все больше вообще подменяли его собой. В разгар перестройки был выпущен толстый том „Русское подвижничество“, где под „подвижничеством“ понималась именно интеллигенция, и только она, а главным подвижником выступал... Корней Чуковский. Из-за этой аберрации, для очень многих людей утверждение о несуществовании интеллигенции равносильно отрицанию всех означенных ценностей и смыслов. На самом же деле, я совсем не вхожу в вопрос, существуют ли у нас ныне эти возвышенные предметы, а констатирую лишь одно: группа „русская интеллигенция“ не является их носителем, по той уважительной причине, что ее нет. Точка. Нелишние вопросы, конечно, - давно ли нет ее, как скончалась. Здесь нет места их обсуждать, отмечу лишь, что кончина случилась уже в постсоветское время. Весь позднесоветский период активно существовал, скажем, самиздат - феномен с бесспорно интеллигентской типологией, датируемое свидетельство существования интеллигенции.

Другая из базовых социальных общностей в дискурсе „Вех“, более широкая, - „общество“. Как и интеллигенция, Общество самоопределяется в своем отношении к Власти, но в этом самоопределении, оно не несет столь крайних свойств как беспочвенность, непременная оппозиционность. Конститутивное отношение может быть очень разным, от тесного сотрудничества, солидарности, до антагонизма, но главное его качество, входящее в само определение Общества как такового, - самостоятельность. Lишь тогда Обще- 
ство есть Общество в настоящем смысле, если оно - полноценный партнер Власти, инстанция, имеющая и продуцирующая самостоятельные позиции во всех областях жизни страны. Ельцинщина была периодом аморфности, когда и Власть, и Общество были равно неспособны репрезентировать себя полноценными сторонами политического и социального процесса. На следующем этапе, Власть преодолела эту свою неспособность, но вместо партнерского содействия Обществу в аналогичном преодолении, стала превращать его в симулякр Общества, лишенный определяющего качества самостоятельности. Неприятие же такой участи пока выражалось и выражается в Обществе лишь на уровне риторики, притом низкокачественной. В итоге, Россия является сегодня однополярной структурой: пространство политическое и социальное заполнено одной Властью, выступающей в двояком виде, - во-первых, в прямом, во-вторых, в виде подставных структур, призванных изображать Общество. Равно как интеллигенции, Общества у нас также нет.

Чего ни хватишься, ничего нет! - как сетовал еще Воланд. Но если уход интеллигенции - в конечном счете, лишь распадение специфического „функционального органа“, не вписавшегося в новую конфигурацию культурно-цивилизационного организма, то Общество - не функциональный орган, а элемент оснований этого организма. Его отсутствие - симптом некой серьезной, опасной недостаточности. Об аналогичной опасности говорят и многие характерные черты постсоветской эпохи, которые я бы объединил под общим названием феноменов иссякания. Иссякания - кого, чего? Вслед за интеллигенцией и Обществом, здесь в поле нашего зрения возникает еще более масштабный предмет, последняя и решающая инстанция - Народ. Только не в смысле интеллигентской мифологемы, а в прямом смысле этнокультурного субъекта и популяционного субстрата национального организма. Этой инстанции русское сознание привыкло всегда приписывать неиссякаемость, привыкло воображать ее необозримой стихией, безмерной толщей, несущей в себе могучую органику, неисчерпаемую творящую и производящую силу. И при всех кризисах и катастрофах, механизм возрождения, в конечном счете, всегда один - опора на эту стихию, питание от ее нутряных сил.

Меж тем, феноменов иссякания уже изрядное множество. Одним из ранних настораживающих примеров можно считать сюрприз первых же месяцев после ухода коммунистического режима: антикоммунистическое движение оказалось абсолютно несостоятельно в качестве силы строительства новой реальности - ни лидеров, ни программ, ни организованных сторонников - вообще собственно никакого „движения“. Недовольство режимом было всеобщим, „народным“ - однако серьезных альтернативных сил в „народе“ не вызрело. (Сравним уход царского режима!) Этим уже как бы предвещался следующий пример, с которого мы начали тему: на сегодняшней стадии, у нас не может никак дозреть, сформироваться „Общество“, ответственные силы, обладающие самостоятельными позициями, несущие в себе опыт осмысления националь- 
ного бытия. Если же взглянуть на всю панораму, включающую и Власть, эти примеры дополнятся антропологическим наблюдением. Ситуация постсоветской России - ситуация исторического вызова, вхождения в новую эпоху, создания новых начал национального бытия. Вызов - в новизне и масштабности задач, он требует творчества и в теории и в практике, требует напряжения сил и, может быть, главное - появления столь же масштабных фигур, вровень с вызовом. Налицо же - обратное. На всей огромной российской сцене не возникает даже просто крупных фигур, чья деятельность хоть отдаленно напоминала бы творческое принятие вызова. Во всем деятельном слое, который определяет процессы жизни государственной и общественной, - лишь мельтешенье неразличимых чиновников, человеческая серость и измельчание: пигмеизащия, как я называю это. Как видим, поле этих феноменов не зависит от политических и иных границ, дело уже не в политике, а много глубже. Тут не оскудевает какойто сектор, будь то левый или правый, а снижается, дегенерирует само качество политической и общественной жизни. Из Народа, производящего лона национальной жизни, не выходит тех, кто принимает вызов истории и осиливает его. И не выходит уж два десятилетия - срок, заставляющий делать выводы.

Прежде чем делать выводы, надо бы попытаться взглянуть и на сам Народ, на „этнокультурного субъекта“ - верно, это тоже объяснит что-нибудь. Тут - своя проблематика, свои процессы, в которые мы не можем сейчас входить; но главные черты, важные для нас, можно увидеть уже из одного выразительного свидетельства. Человек, много работающий в русской глубинке, игумен Кирилл (Сахаров), в недавнем интервью говорит: „Вот и наркотики пришли в деревню... Смертность ужасающая. Ежегодно с карты Тверской области исчезает около 40 деревень... исчезают села, где люди жили столетиями... Главная причина деградации и вымирания - ужасающее пьянство и безработица. Местный житель 50ти лет рассказывал, что из его класса половина мужчин уже умерла от пьянства“. Свидетельство - не единичное, а типичное, и то, что описывается в нем, называют часто звучащим выражением ,демографическая катастрофа““. В аспекте этно-антропологии, это очень напоминает происходившее с малыми народностями при их погружении в чуждую цивилизацию, к патологиям которой у них не было иммунитета. У русской интеллигенции было ритуалом „снимать шапку“ перед народом, мужиком. А я бы сегодня без ритуала, всерьез снял шапку перед русским крестьянином: за то, что для него „чуждой цивилизацией“ оказалось царство Сталина.

Я не думаю утверждать, что в сегодняшней реальности не найдется явлений иного рода, и серия приведенных черт ситуации „бесспорно доказывает“ что-то. Речь вовсе не о доказательствах, а о знаках и предостережениях. Налицо знаки иссякания, истощения родящей силы, Народа, а если скучно-научно - жизненного и творческого ресурса культурно-цивилизационного организма России. И эти знаки суть предостережения - о чем? очевидно, о возможной утрате качества или уровня исторического бытия, возможном переходе в некую 
другую категорию, другую, спортивно выражаясь, лигу всемирной истории. Может быть, „новые русские“, сознание которых свободно от груза истории великой страны, это уже первые пост-русские? Ведь в таком переходе - ничего фантастического, путь этот проходили. Как известно из гимназического фольклора, „Древние греки все вымерли“, хотя и сегодня существует целое государство греков. Концом эпохи Великой России виделся многим „,революционный припадок“, и во время него популярный прозаик написал: „Кончилась Россия, как когда-то кончился Рим“".

В наши дни подобная перспектива все более кажется естественной и все меньше будит протест. Культурная история вся в целом словно стремится „в некую другую лигу“. Человек входит в формацию Виртуального Человека, которому отвечает любопытная культура, не столько творящая, сколько производящая виртуализации, римейки всего что угодно, созданного прежними, актуальными культурами. Бодрийяр это называет „вторичной переработкой“ культуры. А „величие“ - вообще очень не политкорректное понятие.

Но при всем том - выбор еще за нами. Все описанное характеризует тенденции, тренды ситуации, и покуда это - ситуация не „динамической системы“, а человека, обладающего неотчуждаемою свободой, в ней нет предопределенности и не может быть. Человек может преодолеть тренд и повернуть его. Только к этому не могут вести ни ложь о состоянии страны, ни демагогия про „национальную идею“, ни потоки натужно-слабоумного самовосхваления. Даже резкость и чистота критического жеста, усилия, совершенного в „Вехах“, - как учит наш опыт, не обеспечили преодоления. Но знаем точно, что в еще более безнадежных обстоятельствах достиг полного перелома ситуации один грешник: разбойник, распятый рядом со Христом.

Вместо постскриптума. Первый же читатель этого текста сразу спросил: А что это за России в названии? - Но ведь это ясно: со времени „Вех“ успели уйти в небытие две России, Имперская и Советская, а если по-другому считать, то три: Россия Царская - Сталинская - Позднесоветская. Тут ответ очевиден.

Но в том же названии таится и вопрос потруднее: как надо понимать последнее слово в нем - как предлог или деепричастие? 